\title{
Drain Tube-Induced Jejunal Penetration Masquerading as Bile Leak following Whipple's Operation
}

\author{
Sang Ho Bae ${ }^{b}$ Tae Hoon Lee ${ }^{a}$ Sae Hwan Lee ${ }^{a}$ \\ Suck-Ho Lee ${ }^{a}$ Sang-Heum Park ${ }^{a}$ Sun-Joo Kim ${ }^{\text {a }}$ \\ Chang Ho Kim ${ }^{\mathrm{b}}$ \\ ${ }^{a}$ Division of Gastroenterology, Department of Internal Medicine, and \\ ${ }^{b}$ General Surgery, Soonchunhyang University College of Medicine, \\ Cheonan Hospital, Cheonan, South Korea
}

\section{Key Words}

Whipple's operation - Bile leak · Drain tube - Intestinal penetration

\begin{abstract}
A 70-year-old man had undergone pancreaticoduodenectomy due to a distal common bile duct malignancy. After the operation, serous fluid discharge decreased from two drain tubes in the retroperitoneum. Over four weeks, the appearance of the serous fluid changed to a greenish bile color and the patient persistently drained over $300 \mathrm{ml} /$ day. Viewed as bile leak at the choledochojejunostomy, treatment called for endoscopic diagnosis and therapy. Cap-fitted forward-viewing endoscopy demonstrated that the distal tip of a pancreatic drain catheter inserted at the pancreaticojejunostomy site had penetrated the opposite jejunum wall. One of the drain tubes primarily placed in the retroperitoneum had also penetrated the jejunum wall, with the distal tip positioned near the choledochojejunostomy site. No leak of contrast appeared beyond the jejunum or anastomosis site. Following repositioning of a penetrating catheter of the pancreaticojejunostomy, four days later, the patient underwent removal of two drain tubes without additional complications. In conclusion, the distal tip of the catheter, placed to drain pancreatic juice, penetrated the jejunum wall and may have caused localized perijejunal inflammation. The other drain tube, placed in the retroperitoneal space, might then have penetrated the inflamed wall of the jejunum, allowing persistent bile drainage via the drain tube. The results masqueraded as bile leakage following pancreaticoduodenectomy.
\end{abstract}




\section{Introduction}

Although the mortality rate following Whipple's operation has improved (down from historic highs of $25 \%$ to $1.0-1.5 \%$ now at large centers), morbidity and complication rate have remained relatively constant. These complications include delayed gastric emptying, pancreatic fistula, wound infection, hemorrhage, and pancreatitis. Most complications of pancreaticoduodenectomy, while managed without radiologic or endoscopic intervention, demonstrate at imaging. Among complications, bile leak can occur in cases of surgical trauma or injury and infection [1-7]. Bile leak-related complications include injury of the common bile or hepatic ducts, leakage from the cystic duct stump, or transection of the accessory ducts due to anatomic variations. Biliary leaks usually occur in $0.5-3 \%$ of laparoscopic cholecystectomies. Leakage from the cystic duct stumps accounts for the majority of postcholecystectomy leaks. Results of surgical repair of bile duct injuries in comparison to endoscopic therapy are less favorable [8-11]. Surgical methods are associated with high morbidity (22-37\%) and mortality (3-18\%) rates [11-13]. Endoscopic retrograde cholangiopancreatography (ERCP) with biliary stenting is a common method for treating these leaks. In cases of surgical operation such as pancreaticoduodenectomy with choledochojejunostomy, pancreas or bile leak is a problematic complication. However, the strategy of management is not different from what is mentioned above.

We present an unusual, complicated case of intraabdominal drain tube-induced jejunal penetration that masqueraded as bile leak following choledochojejunostomy with pancreaticoduodenectomy due to distal common bile duct (CBD) malignancy. The distal tip of the catheter placed to drain pancreatic juice following pancreaticoduodenectomy penetrated the jejunum wall, and the other drain tube placed in the retroperitoneal space penetrated the inflamed wall of the jejunum, which allowed persistent bile drainage via the drain tube. The results masqueraded as bile leakage following pancreaticoduodenectomy with choledochojejunostomy. To our knowledge, this is the first report describing such a drain tube-related unusual complication following Whipple's operation.

\section{Case Report}

A 70-year-old man presented with symptoms of abdominal pain and jaundice that had started to worsen three days earlier. Upon admission, clinical examination revealed icteric sclera and mild tenderness of the epigastrium. Laboratory tests revealed the following: white blood cell count $7.14 \times 10^{9} / \mathrm{l}\left(4.0-10.8 \times 10^{9} / \mathrm{l}\right)$; total bilirubin $13 \mathrm{mg} / \mathrm{dl}(0.2-1.2 \mathrm{mg} / \mathrm{dl}) ;$ AST $234 \mathrm{IU} / \mathrm{l}(0-40 \mathrm{IU} / \mathrm{l}) ;$ ALT 172 IU/l (0-40 IU/l); amylase 61 IU/l (60-160 IU/l); GTP 512 IU/l (8-48 IU/l); alkaline phosphatase $768 \mathrm{IU} / \mathrm{l}$ (39-117 IU/l); and CA19-9 $479 \mathrm{U} / \mathrm{ml}$ (0-34 U/ml). Abdominal computed tomography and magnetic resonance cholangiopancreatography demonstrated mild upstream biliary tree dilatation with abrupt narrowing of the distal CBD, suggesting distal CBD malignancy, and a few enlarged lymph nodes were noted around the hepatic artery. Subsequently, ERCP showed abrupt distal CBD narrowing, and internal drainage was performed following an endoscopic biopsy and brushing cytology. The pathologic diagnosis was highly suspicious adenocarcinoma, thus pancreaticoduodenectomy (Whipple's operation) was performed.

After pancreaticoduodenectomy with choledochojejunostomy, total bilirubin normalized within 2 weeks, and no immediate postoperative complications developed. Postoperative laboratory findings 2 weeks later showed the following: white blood cell count $5.54 \times 10^{9} / 1$; total bilirubin $1.1 \mathrm{mg} / \mathrm{dl}$; AST 28 IU/l; ALT 13 IU/l; amylase 43 IU/l; and alkaline phosphatase 82 IU/l. The patient had no abdominal symptoms, and serous fluid discharge from two drain tubes in the retroperitoneum decreased after 
Whipple's operation. However, total drainage did not decrease to below $50 \mathrm{ml} /$ day. Over 4 weeks, the serous fluid color changed to a greenish bile color and the patient persistently drained over $300 \mathrm{ml} /$ day. At that time, he had no abdominal pain or irritation signs, except for persistent drainage. Viewed as a bile leak at choledochojejunostomy, endoscopic diagnosis and therapy were planned. Cap-fitted forward-viewing endoscopy (GIF 260; Olympus Optical Co. Ltd., Tokyo, Japan), which is selected for overcoming the difficulty of intestinal angulation due to operation, demonstrated that the distal tip of a pancreatic drain catheter inserted at the pancreaticojejunostomy site had penetrated the opposing jejunum wall (ig. 1) $)$. One of the drain tubes primarily placed in the retroperitoneum had also penetrated the jejunum wall, with the distal tip positioned near the choledochojejunostomy site (fig. 2). After injection of contrast around the choledochojejunostomy site, however, no leakage of contrast appeared beyond the jejunum or anastomosis site (fig. 3). Following repositioning of a penetrating catheter of the pancreaticojejunostomy by endoscopic rat-tooth forceps, the removal of two drain tubes was performed 4 days later because the maturation of drain tube-induced track was accomplished. Following removal of the drain tubes, no additional complication such as bile or pancreatic juice-related leak occurred.

\section{Discussion}

Following pancreaticoduodenectomy, short- and long-term complications arise that, while generally first arousing suspicion on the basis of clinical parameters (fever, leukocytosis and elevation in bilirubin or pancreatic enzyme levels), acquiesce to both imaging diagnosis and imaging-guided intervention. These complications include leaking of digestive enzymes, delayed gastric emptying, pancreatic fistula, wound infection, hemorrhage, and pancreatitis. Among these complications, leaking pancreatic or bile juice may be problematic $[1-3,5-7]$. Pancreatic leak, the most common and dangerous complication, may lead to intraperitoneal abscess, subsequent sepsis, and hemorrhage once the concomitant bile or jejunal leak activates the extravasating pancreatic juice [3]. Since the pancreas is a soft organ, the suture line (from reconnecting it) may not heal very well. This can cause pancreatic juice leakage. Treatment usually involves placing a catheter to catch the drainage [1]. In most patients who have this complication, the leakage heals on its own. However, in the present case, the catheter placed to drain pancreatic juice did not mainly cause the problem. The pancreatic catheter's distal tip penetrated the opposing jejunal wall. Also, another drain tube, necessarily positioned in the retroperitoneal space, was placed near the choledochojejunostomy site after penetration of the jejunal wall (战. 4 ).

Computed tomography usually offers the best means to evaluate fluid collections, abscesses, bile leaks, and bilomas. When one suspects bile leakage in the postoperative period, confirmation of the diagnosis requires visualization of the biliary tract by ERCP to locate the exact site of the defect and to rule out the presence of retained biliary stones. Endoscopic therapy, using either a nasobiliary drain or an internal stent, restores normal bile flow and facilitates leak closure. Endoscopic drainage appears to reduce or eliminate the transpapillary pressure gradient maintained by the sphincter of Oddi, diverting bile preferentially into the duodenum and away from the leakage site [14]. In the present case, we performed abdominal computed tomography, however we had only a limitedly accurate diagnosis at our disposal. Using cap-fitted endoscopy, we diagnosed two drain tubes penetrating the jejunum from the inside to the outside (pancreatic catheter) and from the outside to the inside (intraabdominal drain tube), respectively.

We describe the mechanics of the complication as follows: first, the penetrating drain tube placed in the pancreas may have caused localized perijejunal inflammation. Then, 
the other drain tube-induced penetration around the inflammatory wall of the jejunum occurred, so that persistent bile drainage via the drain tube might have occurred after 4 weeks. We managed this situation by repositioning the drain catheter of the pancreas and by simply removing the external drain tube due to maturation of the fistula track.

\section{Conclusion}

Bile leak following pancreaticoduodenectomy can develop in cases of surgical injury or infection. We present here what we consider the first report of an unusual, delayed complication of drain tube-induced jejunal penetration that masqueraded as bile leak following choledochojejunostomy. In the present case, the distal tip of the catheter, placed to drain pancreatic juice, penetrated the jejunum wall and may have caused localized perijejunal inflammation. The other drain tube, placed in the retroperitoneal space, might then have penetrated the inflamed wall of the jejunum, allowing persistent bile drainage via the drain tube. This caused the complication to masquerade as bile leakage following pancreaticoduodenectomy.

\section{Disclosure Statement}

No financial or other support was granted for this study.
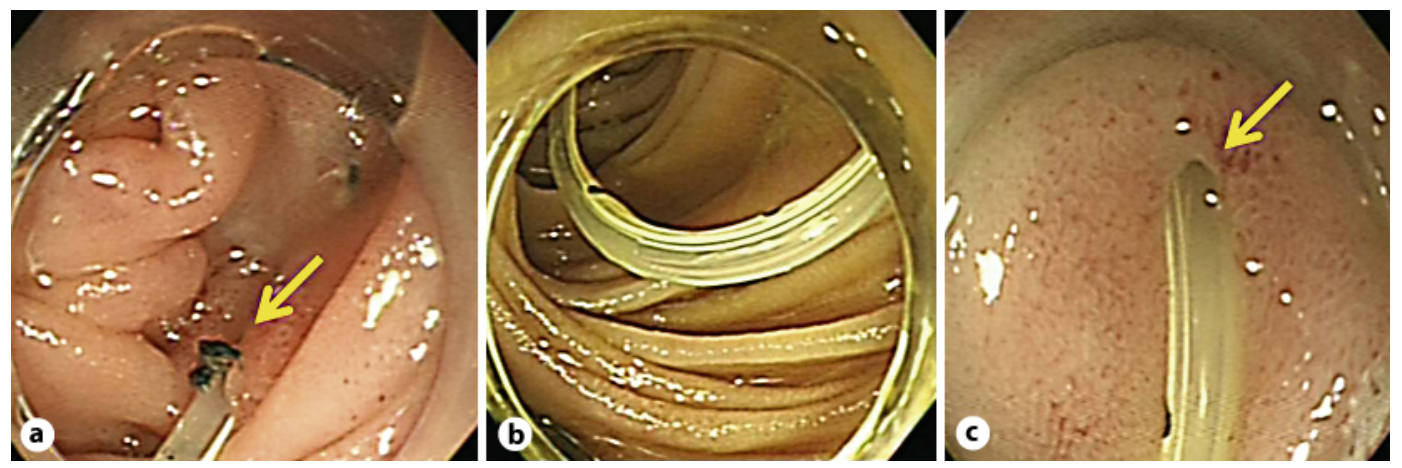

Fig. 1. Endoscopy images. a Cap-fitted endoscopic view demonstrates a pancreatic drain tube inserted in the pancreaticojejunostomy (arrow). The pancreatic drain tube traverses the jejunum (b) and penetrates the opposite jejunal wall (arrow) (c). 


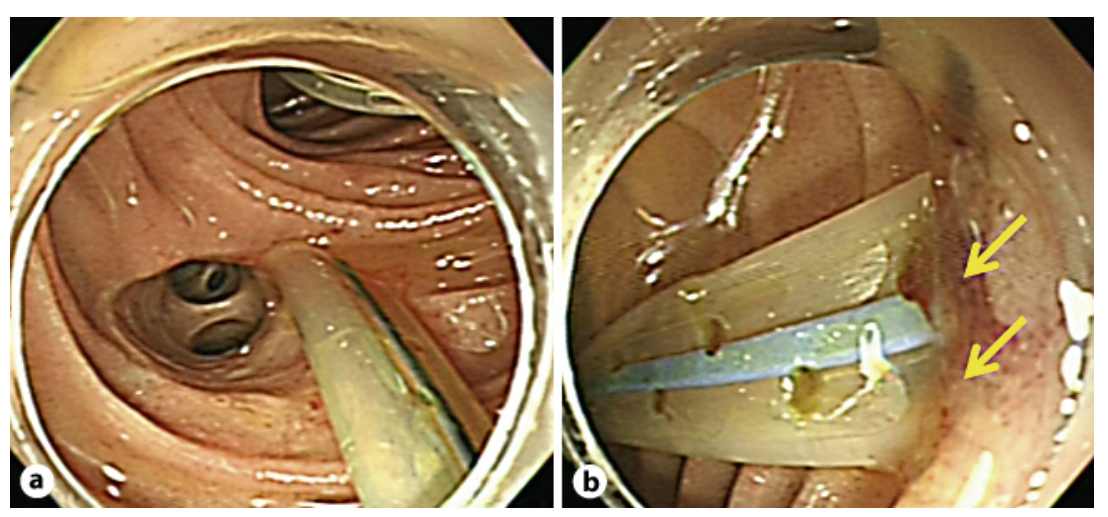

Fig. 2. Endoscopy images. a The distal tip of another intrabdominal drain tube is positioned around the choledochojejunostomy site. b The drain tube has penetrated the jejunal wall (arrows).

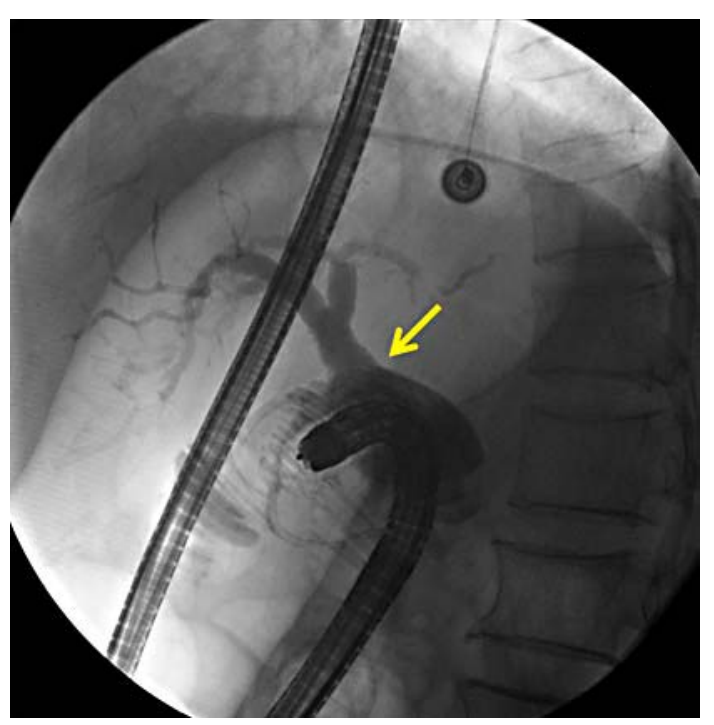

Fig. 3. Fluoroscopy image. Endoscopic view under fluoroscopy shows the choledochojejunostomy without contrast leakage (arrow; anastomosis site). 


\begin{tabular}{|c|c|c|c|}
\hline $\begin{array}{r}\text { Case Reports in } \\
\text { Gastroenterolooy }\end{array}$ & $\begin{array}{l}\text { Case Rep Gastroenterol 2011;5:295-300 } \\
\text { DOI: } 10.1159 / 000329172\end{array}$ & $\begin{array}{l}\text { Published online: } \\
\text { May 23, } 2011\end{array}$ & $\begin{array}{l}\text { () } 2011 \text { S. Karger AG, Basel } \\
\text { ISSN } 1662-0631 \\
\text { www.karger.com/crg }\end{array}$ \\
\hline
\end{tabular}

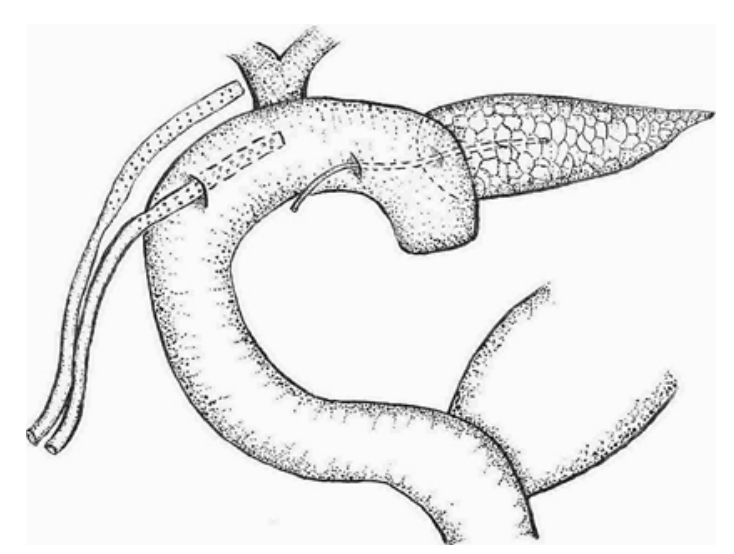

Fig. 4. Hand-drawn illustration showing the position of the complicated two drain tubes.

\section{References}

1 Kazanjian KK, Hines OJ, Eibl G, Reber HA: Management of pancreatic fistulas after pancreaticoduodenectomy: results in 437 consecutive patients. Arch Surg 2005;140:849-854.

-2 Dai XW, Ma K, Wang FX, Yang FQ, Wang BS, Zhao HY, Sun W, Liu BL, Qiu F, Pu XM, Wang L, Dai Y: Prevention of pancreaticojejunal anastomotic leakage after pancreaticoduodenectomy with separate internal drainage of bile and pancreatic fluid. Hepatobiliary Pancreat Dis Int 2003;2:131-134.

-3 Suzuki Y, Fujino Y, Tanioka Y, Ajiki T, Hiraoka K, Takada M, Takeyama Y, Tominaga M, Ku Y, Kuroda Y: Factors influencing hepaticojejunostomy leak following pancreaticoduodenal resection; importance of anastomotic leak test. Hepatogastroenterology 2003;50:254-257.

4 Putcha RV, Burdick JS: Management of iatrogenic perforation. Gastroenterol Clin North Am 2003;32: 1289-1309.

-5 Ramacciato G, Mercantini P, Petrucciani N, Nigri GR, Kazemi A, Muroni M, Del Gaudio M, Balesh A, Cescon M, Cucchetti A, Ravaioli M: Risk factors of pancreatic fistula after pancreaticoduodenectomy: a collective review. Am Surg 2011;77:257-269.

6 Suzuki S, Kaji S, Koike N, Harada N, Hayashi T, Suzuki M, Imaizumi T, Hanyu F: Pancreaticoduodenectomies with a duct-to-mucosa pancreaticojejunostomy anastomosis with and without a stenting tube showed no differences in long-term follow-up. J Hepatobiliary Pancreat Sci 2011;18:258-262.

7 Papadimitriou JD, Fotopoulos AC, Smyrniotis B, Prahalias AA, Kostopanagiotou G, Papadimitriou LJ: Subtotal pancreatoduodenectomy: use of a defunctionalized loop for pancreatic stump drainage. Arch Surg 1999;134:135-139.

8 Southern Surgeons Club: A prospective analysis of 1,518 laparoscopic cholecystectomies. N Engl J Med 1991;324:1073-1078.

-9 Peters JH, Gibbons GD, Innes JT, Nichols KE, Front ME, Roby SR, Ellison EC: Complications of laparoscopic cholecystectomy. Surgery 1991;110:769-777.

10 Rossi RL, Schirmer WJ, Braasch JW, Sanders LB, Munson JL: Laparoscopic bile duct injuries. Risk factors, recognition, and repair. Arch Surg 1992;127:596-602.

11 Martin RF, Rossi RL: Bile duct injuries: spectrum, mechanisms of injury and their prevention. Surg Clin North Am 1994;74:781-803.

12 Hillis TM, Westbrook KC, Caldwell FT, Read RC: Surgical injury of the common bile duct. Am J Surg 1977;134:712-716.

13 Kune G: Bile duct injury during cholecystectomy: causes, prevention and surgical repair in 1979. Aust N Z J Surg 1979;49:35-40.

14 Fathy O, Wahab MA, Elghwalby N, Sultan A, EL-Ebidy G, Hak NG, Abu Zeid M, Abd-Allah T, El-Shobary M, Fouad A, Kandeel T, Abo Elenien A, Abd El-Raouf A, Hamdy E, Sultan AM, Hamdy E, Ezzat F: 216 cases of pancreaticoduodenectomy: risk factors for postoperative complications. Hepatogastroenterology 2008;55: 1093-1098. 